\title{
Social media apps used by immigrants in the United States: challenges and opportunities for public health research and practice
}

\author{
Y. Alicia Hong ${ }^{1 \wedge}$, Hee-Soon Juon ${ }^{2} \wedge$, Wen-Ying Sylvia Chou ${ }^{3} \wedge$ \\ ${ }^{1}$ Department of Health Administration and Policy, College of Health and Human Services, George Mason University, Fairfax, VA, USA; ${ }^{2}$ Division \\ of Population Science, Department of Medical Oncology, Thomas Jefferson University, Philadelphia, PA, USA; ${ }^{3}$ Health Communication and \\ Informatics Research Branch, Behavioral Research Program, National Cancer Institute, Rockville, MD, USA \\ Correspondence to: Y. Alicia Hong, PhD. Professor, Department of Health Administration and Policy, College of Health and Human Services, George \\ Mason University, 4400 University Dr. MS 1j3, Fairfax, VA 22030, USA. Email: yhong22@gmu.edu.
}

Received: 02 August 2020; Accepted: 06 December 2020; Published: 20 October 2021.

doi: $10.21037 /$ mhealth-20-133

View this article at: http://dx.doi.org/10.21037/mhealth-20-133

\section{Social media use landscape: ubiquity and diversity}

More than $81 \%$ of Americans owned a smartphone in 2019, up from $35 \%$ in 2011, and most smartphone users use social media apps almost daily (1). Social media can reach millions of people with health information and advice, yet it is also a significant source of misinformation and disinformation (2). Regardless of its positive and negative effects, for most Americans, social media has become the hub of social networking and an importantand sometimes primary-source of health information. Within the ubiquitous social media landscape is a growing body of research on the role that social media plays in public health $(3,4)$.

Popular platforms, such as Facebook and Twitter, with billions of users, are the dominant players on the evercrowded field of social media apps; they also represent mainstream English-speaking users in the United States (U.S.). However, more than 67 million Americans speak a foreign language at home. In addition to 37 million Spanish speakers, 2.9 million speak Chinese, 2 million French, 1.6 million Tagalog, 1.4 million Vietnamese, and 1.1 million Korean, just to name a few (5). Many of these people are first- or second-generation immigrants, representing vulnerable and underserved communities and those suffering from growing health disparities and a digital health divide.

The ownership of smartphones among minorities and immigrants is greater than $90 \%$ as low-income populations are more likely to be smartphone-dependent, with a smartphone being the only mobile device they own (6). In addition to high rates of smartphone ownership, use of social media apps is as diverse as the immigrant groups themselves. Because of their linguistic and cultural preferences, and the need to stay connected with family and friends in their country of origin, immigrants use a variety of social media apps. For example, WhatsApp, used widely in Africa and Southeast Asia, has 1.6 billion global users; VK, used widely in Europe, has 300 million users. People in different countries have their own favored social media apps. For example, WeChat, commonly used by Chinese people, has over 1.1 billion global users; Kaokao talk holds $96 \%$ of the market share in South Korea and has more than 50 million active global users; and Zalo, the most popular social media app in Vietnam, has over 100 million global users (7).

\section{Gaps in the existing social media-based public health programs}

Existing studies on social media and public health were

^ ORCID: Y. Alicia Hong, 0000-0002-1481-6495; Hee-Soon Juon, 0000-0001-7837-7009; Wen-Ying Sylvia Chou, 0000-0002-9140-6094. 
mostly descriptive (8). A small number of social mediabased interventions have shown initial effectiveness in promoting HIV testing and medication adherence (9), cancer prevention (8), smoking cessation (10), and sexual health education (11). Most programs were delivered via the "mainstream" apps such as Facebook and Twitter (11-13). In addition to a lack of diversity of delivery channels, few social media-based interventions are designed for immigrants or minorities (8). For example, a recent review of studies on social media for health promotion in Hispanic populations and found almost all studies were descriptive without any intervention (14). Existing social media-based intervention studies reported very low rates of participation of minority populations; and the participating minorities had lower levels of engagement compared to their white counterparts $(8,12,13)$. In our own literature search, we did not find any social media health interventions that targeted immigrants.

Lack of diversity is also exhibited in online presentation and research dissemination. For example, a recent study that analyzed images on social media and online platforms of hospitals in Washington, D.C., found that racial and ethnic minorities are significantly under-represented (15). Brownson and colleagues reported that the most used social media platform for dissemination of research findings was Twitter (16). Notably, Twitter users are typically younger, highly educated, urban whites and may not represent the general American population, let alone individuals from underserved communities (17).

\section{Challenges faced by immigrants in the social media era}

The scarcity of social media-based health promotion programs for immigrants and a lack of diversity in social media platforms to deliver these programs presents significant challenges in addressing health disparities in diverse communities. First, immigrants have a dire need for targeted social media health campaigns. Health information and cultural beliefs are shared in communities. Because of the closely knitted social networks, immigrants are more likely to fall into information silos with less crosstalk or exchange of diverging viewpoints. The opaque algorithms of social media that feed information based on browsing history makes it more difficult to break these information silos. As a result, immigrants may be more likely to fall prey to misinformation. For example, African immigrants in the U.S. have been exposed to much misinformation about cervical cancer, they also had low HPV vaccination rates and high cervical cancer mortality rates (18).

Second, as more public health information and interventions are delivered online, immigrants are more likely to be excluded from evidence-based public health communication efforts, further widening existing health disparities. This gap is more dangerous in the era of social media; when people do not receive timely information from credible sources to address the uncertain or unknown, they are more likely to fill the vacuum by seeking information from their trusted groups on social media. For example, the lack of culturally appropriate HIV interventions for Hispanics has contributed to a rapid increase of HIV transmission in the vulnerable population (19).

Third, immigrants and minorities are more likely to have lower levels of health literacy because of cultural and linguistic barriers. Social media apps enable delivery of public health programs in multimedia format, such as short video clips or pictorial messages, to address the barriers of health literacy. However, to date, such efforts are rather limited. For example, Asian Americans have elevated liver cancer mortality rates due to low awareness of chronic hepatitis $\mathrm{B}$ infection and limited screening (20); but there is virtually no linguistically appropriate liver cancer prevention programs delivered via social media apps commonly used by Asian Americans.

\section{Recommendations for social media-based public health research and practice for immigrants}

Social media is intricately embedded in our daily lives, and research has revealed its health-related benefits and harms. The opportunity to reach and serve marginalized immigrants may be missed if we do not harness social media tools for public health. In this endeavor, we make the following recommendations.

First, more research is needed on patterns and preferences of social media use in immigrants. Academiaindustry partnerships and interdisciplinary research are crucial in collecting and analyzing relevant data. Data can be collected from mixed method research as well as artificial intelligence (AI)-assisted retrieval of big data from social media platforms. Newly developed AI-assisted analytical tools for multilingual data can facilitate the process (21).

Second, we need more evidence on feasibility and effectiveness of social media-based interventions for these marginalized groups (22). These studies should be built upon strong partnerships with health service providers and community organizations. Such partnerships can reflect 
values and priorities of communities, and collaboratively examine how to efficiently use social media platforms in needs assessment, service delivery, program evaluation, and scientific information dissemination.

Third, we need to enhance our training on cultural competence, i.e., practice that respects diversity in the population and cultural factors that can affect health and healthcare (e.g., language, communication styles, beliefs, attitudes, behaviors) (23). Cultural competence training should include adoption of preferred social media apps and understanding of usage patterns in the populations served. As social media has become an important channel of communication and networking; the choice of platform reflects one's sense of belonging and cultural identity. Public health professionals need to be equipped with necessary app-use skills and cultural competence to utilize social media tools to access, negotiate, and create health information that is actionable and impactful for diverse audiences (24).

\section{Conclusions}

To conclude, ubiquitous social media use has presented unprecedented challenges and opportunities for public health research and practice. The diversity of social media use in immigrant groups has been understudied; digital inequality associated with social media-based public health programs would exacerbate existing health disparities. It is time for more research on patterns of social media use among immigrant groups as well as the development of health interventions on non-mainstream social media apps in order to reach these groups. Enhanced cultural competency training related to social mediabased interventions for minorities and immigrants is also critical. These efforts require innovative partnerships of health organizations, technology industry, academia, and community stakeholders.

\section{Acknowledgments}

We appreciate very constructive comments from Drs. Robin Vanderpool and William Klein from the National Cancer Institute.

Funding: None.

\section{Footnote}

Provenance and Peer Review: This article was a standard submission to the journal. The article has undergone external peer review.

Peer Review File: Available at http://dx.doi.org/10.21037/ mhealth-20-133

Conflicts of Interest: All authors have completed the ICMJE uniform disclosure form (available at http://dx.doi. org/10.21037/mhealth-20-133). The authors have no conflicts of interest to declare.

Ethical Statement: The authors are accountable for all aspects of the work in ensuring that questions related to the accuracy or integrity of any part of the work are appropriately investigated and resolved.

Open Access Statement: This is an Open Access article distributed in accordance with the Creative Commons Attribution-NonCommercial-NoDerivs 4.0 International License (CC BY-NC-ND 4.0), which permits the noncommercial replication and distribution of the article with the strict proviso that no changes or edits are made and the original work is properly cited (including links to both the formal publication through the relevant DOI and the license). See: https://creativecommons.org/licenses/by-nc-nd/4.0/.

\section{References}

1. Pew Research Center. Mobile Fact Sheet. Available online: https://www.pewresearch.org/internet/fact-sheet/mobile/ (Accessed November 15, 2020).

2. Chou WS, Oh A, Klein WMP. Addressing health-related misinformation on social media. JAMA 2018;320:2417-8.

3. Arigo D, Jake-Schoffman DE, Wolin K, et al. The history and future of digital health in the field of behavioral medicine. J Behav Med 2019;42:67-83.

4. Giustini D, Ali SM, Fraser M, et al. Effective uses of social media in public health and medicine: a systematic review of systematic reviews. Online J Public Health Inform 2018;10:e215.

5. Zeigler K, Camarota SA. 67.3 Million in the United States Spoke a Foreign Language at Home in 2018. Available online: https://cis.org/Report/673-Million-UnitedStates-Spoke-Foreign-Language-Home-2018 (Accessed November 20, 2020).

6. Tsetsi E, Rains SA. Smartphone Internet access and use: extending the digital divide and usage gap. Mobile Media \& Communication 2017;5:239-55. 
7. Statistica. Social Media \& User-Generated Content. Available online: https://www.statista.com/markets/424/ topic/540/social-media-user-generated-content/ (Accessed November 15, 2020).

8. Koskan A, Klasko L, Davis SN, et al. Use and taxonomy of social media in cancer-related research: a systematic review. Am J Public Health 2014;104:e20-37.

9. Cao B, Gupta S, Wang J, et al. Social media interventions to promote HIV testing, linkage, adherence, and retention: systematic review and meta-analysis. J Med Internet Res 2017;19:e394.

10. Naslund JA, Kim SJ, Aschbrenner KA, et al. Systematic review of social media interventions for smoking cessation. Addict Behav 2017;73:81-93.

11. Gabarron E, Wynn R. Use of social media for sexual health promotion: a scoping review. Glob Health Action 2016;9:32193.

12. Johns DJ, Langley TE, Lewis S. Use of social media for the delivery of health promotion on smoking, nutrition, and physical activity: a systematic review. Lancet 2017;390:S49.

13. Welch V, Petkovic J, Pardo Pardo J, et al. Interactive social media interventions to promote health equity: an overview of reviews. Health Promot Chronic Dis Prev Can 2016;36:63-75.

14. Hudnut-Beumler J, Po'e E, Barkin S. The use of social media for health promotion in Hispanic populations: a scoping systematic review. JMIR Public Health Surveill 2016;2:e32.

15. Myers T, Richardson F, Chung JE. Racial and Ethnic Makeup in Hospital's Social Media and Online Platforms: Visual Representation of Diversity in Images and Videos of Washington, D.C. Hospitals. J Health Commun 2019;24:482-91.

16. Brownson RC, Eyler AA, Harris JK, et al. Getting the

doi: $10.21037 /$ mhealth-20-133

Cite this article as: Hong YA, Juon HS, Chou WYS. Social media apps used by immigrants in the United States: challenges and opportunities for public health research and practice. mHealth 2021;7:52. word out: new approaches for disseminating public health science. J Public Health Manag Pract 2018;24:102-11.

17. Wojcik S, Hughes A. Sizing Up Twitter Users. Pew Research Centers. 2019. Available online: https:// www.pewresearch.org/internet/wpcontent/uploads/ sites/9/2019/04/twitter_opinions_4_18_final_clean.pdf (Accessed November 15, 2020).

18. Hurtado-de-Mendoza A, Song M, Kigen O, et al. Addressing cancer control needs of African-born immigrants in the US: a systematic literature review. Prev Med 2014;67:89-99.

19. Guilamo-Ramos V, Thimm-Kaiser M, Benzekri A, et al. The Invisible US Hispanic/Latino HIV Crisis: Addressing Gaps in the National Response. Am J Public Health 2020;110:27-31.

20. Chen MS Jr, Dang J. Hepatitis B among Asian Americans: prevalence, progress, and prospects for control. World J Gastroenterol 2015;21:11924-30.

21. Lorini V, Castillo C, Dottori F, et al. Integrating social media into a pan-european flood awareness system: a multilingual approach. 2019. arXiv:1904.10876.

22. Pagoto S, Waring ME, Xu R. A call for a public health agenda for social media research. J Med Internet Res 2019;21:e16661.

23. Butler M, McCreedy E, Schwer N, et al. Improving cultural competence to reduce health disparities. Agency for Healthcare Quality Research. 2014. Available online: https://effectivehealthcare.ahrq.gov/sites/default/files/ pdf/cultural-competence_research-protocol.pdf (Accessed November 15, 2020).

24. Stellefson M, Paige SR, Chaney BH, et al. Evolving role of social media in health promotion: updated responsibilities for health education specialists. Int J Environ Res Public Health 2020;17:1153. 